AperTO - Archivio Istituzionale Open Access dell'Università di Torino

\title{
A mass spectrometric analysis of sensitizer solution used for dye-sensitized solar cell
}

\section{This is the author's manuscript}

Original Citation:

Availability:

This version is available http://hdl.handle.net/2318/26818

since

Published version:

DOI:10.1016/j.ica.2007.07.016

Terms of use:

Open Access

Anyone can freely access the full text of works made available as "Open Access". Works made available under a Creative Commons license can be used according to the terms and conditions of said license. Use of all other works requires consent of the right holder (author or publisher) if not exempted from copyright protection by the applicable law. 


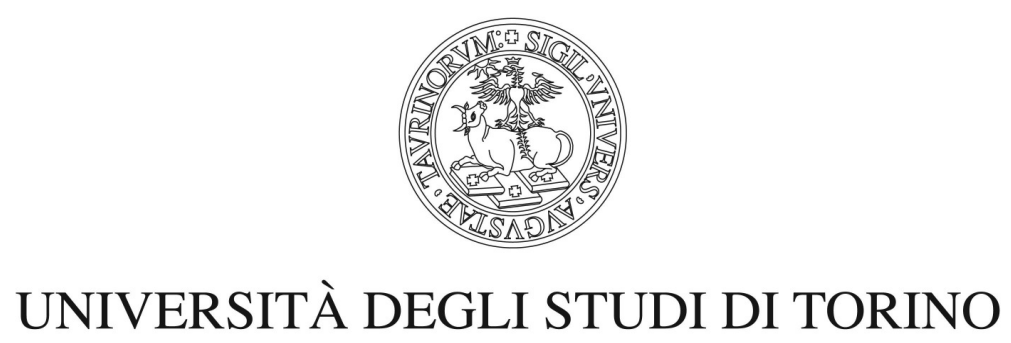

This Accepted Author Manuscript (AAM) is copyrighted and published by Elsevier. It is posted here by agreement between Elsevier and the University of Turin. Changes resulting from the publishing process - such as editing, corrections, structural formatting, and other quality control mechanisms - may not be reflected in this version of the text. The definitive version of the text was subsequently published in Inorganica Chimica Acta 361, 798-805, 2008, 10.1016/j.ica.2007.07.016.

You may download, copy and otherwise use the AAM for non-commercial purposes provided that your license is limited by the following restrictions:

(1) You may use this AAM for non-commercial purposes only under the terms of the CC-BY-NC-ND license.

(2) The integrity of the work and identification of the author, copyright owner, and publisher must be preserved in any copy.

(3) You must attribute this AAM in the following format: Creative Commons BY-NC-ND license (http://creativecommons.org/licenses/by-nc-nd/4.0/deed.en), [10.1016/j.ica.2007.07.016]. 


\title{
A Mass Spectrometric Analysis of Sensitizer Solution used for Dye-Sensitized Solar Cell
}

\author{
Roberto Buscaino, ${ }^{1}$ Claudio Baiocchi, ${ }^{2}$ Claudia Barolo, ${ }^{1}$ Claudio Medana, ${ }^{2}$ Michael Grätzel, ${ }^{3}$ Md.
} K. Nazeeruddin, ${ }^{3}$ Guido Viscardi ${ }^{1 *}$.

${ }^{1}$ Dipartimento di Chimica Generale ed Organica Applicata, Center of Excellence for Nanostructured Interfaces and Surfaces, Università di Torino, Corso Massimo D'Azeglio, 48, 10125 Torino, Italy

${ }^{2}$ Dipartimento di Chimica Analitica, Università di Torino, Via Pietro Giuria, 5, 10125 Torino, Italy

${ }^{3}$ Laboratory for Photonics and Interfaces, Institute of Chemical Sciences and Engineering, School of basic Sciences, Swiss Federal Institute of Technology, CH - 1015 Lausanne, Switzerland

\begin{abstract}
We report a mass spectrometric study of ruthenium(II) sensitizer $\left(\left(\mathrm{C}_{4} \mathrm{H}_{9}\right)_{4} \mathrm{~N}\right)_{2}[\mathrm{Ru}(4$-carboxy-4'carboxylate-2,2'bipyridine $\left.)_{2}(\mathrm{NCS})_{2}\right](\mathrm{N} 719)$ in various organic and aqueous solvents. At the equilibrium different species were found, depending on solution properties. After stoichiometry confirmation through high-resolution mass spectra and isotopic pattern analysis, the formation of these complexes was found to strongly depend from the polarity and the ionic strength of solvent medium. Mass spectra obtained in acetonitrile/tert-butanol (1:1) mixture, used for the absorption of N719 on $\mathrm{TiO}_{2}$, suggests that the main species involved in the adsorption process is the dicarboxylate form of $\mathrm{N} 719$ with one $\left(\mathrm{C}_{4} \mathrm{H}_{9}\right)_{4} \mathrm{~N}$ as counter ion. The photovoltaic data of the N719 sensitizer adsorbed on $\mathrm{TiO}_{2}$ films exhibited remarkable power conversion efficiency, $11.20 \%$ at 1 sun.
\end{abstract}

Keywords: Ru(II) complex; ESI-MS; noncovalent complexes; N719 sensitizer, Dye-sensitized solar cell. 


\section{Introduction}

Dye sensitized solar cells are currently attracting widespread academic and commercial interest for conversion of sunlight into electricity because of its low cost and high efficiency. ${ }^{[1-23]}$ At the heart of the system is a mesoporous oxide layer composed of nanometer-sized particles, and the sensitizer, which allows electronic conduction and harvesting of solar radiation, respectively. Various ruthenium complexes containing anchoring groups such as carboxylic acid, dihydroxy, and phosphonic acid on pyridine ligands have been used as sensitizers. ${ }^{[24]}$ The anchoring groups serve to immobilize the sensitizer onto nanocrystalline $\mathrm{TiO}_{2}$ surface, that upon photoexcitation injects electrons into the $\mathrm{TiO}_{2}$ conduction band and the concomitant hole transfer to the redox electrolyte. $^{[25][26]}$

The anchoring groups of the sensitizer that contain protons, upon adsorption, transfers most of its protons to the $\mathrm{TiO}_{2}$ surface charging it positively and thereby the Fermi level moves down (positively). However, the positive shift of the Fermi level decreases the gap between the redox couple iodide/triiodide and the Fermi level, resulting in lower open-circuit potential. On the other hand, if the sensitizer carries zero protons, then the Fermi level moves negatively, due to adsorption of anionic complex, and the cations thereby a higher value for open-circuit potential while that of short circuit current is low. ${ }^{[27,28]}{ }^{[29]}$ Therefore, there should be an optimal degree of protonation of the sensitizer for which the product of short circuit photocurrent and open circuit potential is high that determines the power conversion efficiency of the cell.

Cis-dithiocyanato bis(4-carboxy-4'-carboxylate-2,2'-bipyridine)ruthenium(II) ditetrabutylammonium salt, (N719), is a high performance sensitizer in Grätzel photovoltaic cells ${ }^{[30]}$. It is adsorbed on mesoporous anatase $\mathrm{TiO}_{2}$ as tetrabutylammonium double salt from a solution of acetonitrile/tert-butanol (1:1) mixture. The two hydrophobic cations were used in order to increase the solubility of sensitizer in organic solvent.

The high performance achieved using $\left(\left(\mathrm{C}_{4} \mathrm{H}_{9}\right)_{4} \mathrm{~N}\right)_{2}[\mathrm{Ru}(4$-carboxy-4'-carboxylate-22'bipyridine $)_{2}(\mathrm{NCS})_{2}$ ] (N719) sensitized $\mathrm{TiO}_{2}$ solar cell can be related to several factors, such as 
broad range of visible light absorption, relatively long-lived excited states, its excited energy almost matching those of $\mathrm{TiO}_{2}$ conduction band, and the effect of protons and the cations carried by the sensitizer. It is therefore important to analyze in detail the structure of the sensitizer from adsorbing solution in order to design and develop tailored sensitizers. In this paper, we report detailed HPLC (High Pressure Liquid Chromatography) and mass analysis of the N719 sensitizer.

\section{Experimental}

HPLC analyses were performed on a Shimadzu HPLC 10-AVP series equipped with a photodiode array SPD-M 10 Avp as detector using as solid phase a Luna C-18 (2) column 4.6 mm x $250 \mathrm{~mm}$ with particle size of $5 \mu \mathrm{m}$, and water/acetonitrile $1: 1$, added with $0.1 \%$ of formic acid as liquid phase, at a flow rate of $1 \mathrm{ml} / \mathrm{min}$. ESI (Electro Spray Ionization) experiments were conducted with a Thermo Finnigan Advantage Max Ion trap spectrometer in negative ion acquiring mode; sheath gas flow rate was set at 25 (arbitrary unit), auxiliary gas flow rate at 5 (arbitrary unit), spray voltage at $3.25(\mathrm{KV})$, capillary temperature at $270{ }^{\circ} \mathrm{C}$, capillary voltage at $-7(\mathrm{~V})$, and tube lens offset at $-60.00(\mathrm{~V})$. Nitrogen was used as sheath and auxiliary gas. High-resolution spectra were recorded on a LTQ Orbitrap Hybrid Mass Spectrometer. Sprayed solutions were prepared starting from a mother solution, obtained solving $13.8 \mathrm{mg}$ of complex in $10 \mathrm{ml}$ of acetonitrile/tert-butanol (1:1); $1 \mathrm{ml}$ of the mother solution was diluted to $10 \mathrm{ml}$ by adding i) acetonitrile/tert-butanol (1:1) mixture, ii) $5 \%$ aqueous methanol solution, and iii) an aqueous solution of ammonium acetate $5 \mathrm{mM}$ added with $5 \%$ of methanol. The solution at basic $\mathrm{pH}$ was obtained by adding to aqueous solution some drops of a $30 \%$ ammonium hydroxide solution to obtain a concentration solution $0.1 \mathrm{~N}$; $\mathrm{pH}$ was monitored using a pH-metre Crison Basic 20 equipped with a glass electrode Crison 52-02, the reported working $\mathrm{pH}$-range is 0-12; solvents used for MS analysis were purchased from Aldrich and were used without further purification.

The synthesis of N719 sensitizer was reported in our previous paper. ${ }^{[10,}$ 31] The chromatographic purification of N719 was carried out three times on a column of Sephadex LH-20 using the following procedure. The N719 complex was dissolved in water containing two 
equivalents of tetrabutylammonium hydroxide. The concentrated solution was filtered through a sintered glass crucible and charged onto a Sephadex LH-20 column, which was prepared in water. The adsorbed complex was eluted using water. The main band was collected and the solution $\mathrm{pH}$ was lowered to 4.3 using $0.02 \mathrm{M} \mathrm{HNO}_{3}$ acid. The titration was carried out slowly over a period of three hours. Then, the solution was kept at $-20{ }^{\circ} \mathrm{C}$ for 15 hours. After allowing flask to $25{ }^{\circ} \mathrm{C}$, the precipitated complex was collected on a glass frit and air-dried. The same purification procedure was repeated two more times to get pure N-bonded isomer complex.

\section{Results and Discussion}

Purified N719 was analysed by HPLC using a diode array as detector. HPLC run, reported in Fig. 1a, shows only one peak. Spectral homogeneity across the peak evidences that no coelution occurred, confirming N719 purity (Fig. 1b). The interaction between the solid phase and the TBA counterions of the $\mathrm{Ru}(\mathrm{II})$ complex is responsible for the tailored shape of the peak. Structure of complex was confirmed by the integration ratio of aliphatic and aromatic ${ }^{1} \mathrm{H}-\mathrm{NMR}$ signals and elemental analyses. ${ }^{[32]}$

In order to characterize charged complexes involved during $\mathrm{N} 719$ adsorption on $\mathrm{TiO}_{2}$ surface, Mass Spectrometry with ESI interface appeared particularly useful because: ${ }^{[33]}$ (i) it can directly detect mono and multi-charged ion, (ii) does not alter the connectivity of the complex through disassembly/reassembly sequences and (iii) causes essentially no or very little fragmentation. Recently, Newkome and Wesdemiotis applied this technique to study organometallic assemblies containing bis-terpyridinyl-Ru(II) connectivity. ${ }^{[34]}$

A mother solution of N719 in acetonitrile/tert-butanol (1:1) was prepared at the same concentration of that used for the adsorption on $\mathrm{TiO}_{2}$, then diluted 1:10 to obtain a concentration useful to record mass spectrum by direct injection method.

The mass spectrum reported in Fig. 2 shows a major peak at m/z 946.1 and two minor peaks at $\mathrm{m} / \mathrm{z} 704.9$ and at $\mathrm{m} / \mathrm{z} 1187.5$. Solvents of relative lipophilic character favour the dissociation of 
one of the two ion pairs of N719 complex, solvating the hydrophobic TBA cation, and the monoanion (E) (Scheme 1) is mainly observed. Its stoichiometry is confirmed by isotopic pattern as shown in Fig. 3a. On this peak tandem mass spectrometry analysis was performed in order to obtain more structural informations. The complicate fragmentation obtained in MS/MS spectrum, revealed that the interactions between the $\mathrm{Ru}(\mathrm{II})$ centre and the two bipyridine ligands are very strong. The assignation of the small peak at $\mathrm{m} / \mathrm{z} 704.9$ required the use of high resolution mass spectrometry technique. In Fig. $3 \mathrm{~b}$ are reported experimental and calculated isotopic pattern of peak at m/z 704.9, corresponding to the mono-anion $\mathrm{Ru}(\mathrm{II})$ complex (B) (Scheme 1) with no counter ion. The dissociation of both ion couples would give an unstable di-anion: extraction of a hydrogen atom from the protic solvent gives a more stable tricarboxylic mono-anion complex (B) (Scheme 1).

To confirm that the observed species were not instrumental artefact, we tried to decrease the ion count within the ion trap. In this way, if observed species were created in the mass analyzer they probably disappear. However, in our case, species evidenced in normal analysis conditions were still observed. Moreover, solutions were monitored for about 48 hours and no changes were observed indicating that equilibria among stable species in different solutions are reached within few minutes.

The use of solvent systems with different polarity can be useful to evidence that minor species are not impurities but members of the $\mathrm{Ru}(\mathrm{II})$ complex-TBA acid-base equilibrium. Fig. 4 shows the mass spectrum of N719 complex in a solution obtained diluting $1 \mathrm{ml}$ of mother solution in acetonitrile/tert-butanol (1:1) with $9 \mathrm{ml}$ of a $5 \%$ aqueous methanol solution. The addition of methanol is necessary to assist water evaporation during ESI experiments.

Along with the main peak at m/z 946.1, ESI analysis evidenced a peak at m/z 1187.5 of comparable intensity with the former, and a less intense peak at m/z 593.2 and a very small peak at m/z 1428.8. Solvation of TBA in water is not so effective as in tert-butanol/acetonitrile, and the organic cation tends to form the ion pair with the carboxylic group. As a consequence, the peak at $\mathrm{m} / \mathrm{z} 1187.5$, corresponding to tri-carboxylate species with two TBA counterions (F) (Scheme 1), increases and 
the small peak at $\mathrm{m} / \mathrm{z}$ 1428.8, corresponding to tetra-carboxylate species with three TBA counterions (G) (Scheme 1), appears. The higher polarity of solution favours also the formation of double-charged anions. So, the peak at $\mathrm{m} / \mathrm{z}$ 593.2, attributed to species (D) (Scheme 1), becomes observable and its stoichiometry is confirmed by isotopic pattern (Fig. 5a). The assignation of peak at $\mathrm{m} / \mathrm{z} 473.9$ presented some difficulties; isotopic pattern of this peak, obtained with low resolution mass instrument, suggested the presence of compound $(\mathbf{C})$ with $\mathrm{z}=2$ and exact mass 472.6 but the overlay of isotopic peaks separated by an half mass unit $(\mathrm{z}=2)$ with similar mass signals generates an apparent mass shift. To verify the assignment with higher accuracy, we performed an analysis with a high resolution instrument. The obtained isotopic pattern is reported in Fig. $5 \mathrm{~b}$ and confirm the formation of compound $(\mathbf{C})$.

The addition of ammonium acetate $5 \mathrm{mM}$ to the above aqueous solution brought once more changes in mass spectrum (Fig. 6). Using this volatile salt we were able to study the effect of an increase in ionic strength of solvent medium. Moreover, we could evaluate the intensity of TBAcarboxylate interaction monitoring the occurring of exchange reaction between TBA, counter ion of the $\mathrm{Ru}(\mathrm{II})$ complex, and the ammonium cation of electrolyte. Under these conditions, three peaks at $\mathrm{m} / \mathrm{z}$ 946.1, 1187.5 and 1428.8 appeared with a ratio of about 1:1:1, as evidenced in Fig. 6 . The marked increase of stability of species $\mathbf{F}$ and, in particular, of species $\mathbf{G}$ (m/z 1428.8) suggests that the presence of electrolyte favours the association of the lypophilic TBA to carboxylate. Also in this case the isotopic pattern analysis, reported in Fig. 7a, and Fig. 7b, confirms respectively species $\mathbf{F}$ and $\mathbf{G}$.

The isotopic patterns confirm peaks assignation. No peaks due to ammonium/TBA exchange are detectable, suggesting the formation of a strong ion pair between $\mathrm{Ru}(\mathrm{II})$ complex and TBA.

To further confirm the behaviour of TBA in polar solvent system, we set at 11 the $\mathrm{pH}$ value of the diluted aqueous (5\% methanol) solution adding ammonium hydroxide to obtain $0.1 \mathrm{~N}$ solution. In Fig. 8, ESI analysis is reported. The base induces the dissociation of carboxylic groups, as confirmed by the prevalence of peak at $\mathrm{m} / \mathrm{z}$ 1428,8 stabilized with the formation of three strong ion 
pairs. Also in this case no exchange reaction between TBA, counter ion of the $\mathrm{Ru}(\mathrm{II})$ complex, and ammonium species occurred.

The N719 dye solution containing the monoprotonated species was prepared in 1:1 $\mathrm{CH}_{3} \mathrm{CN}+$ tert-BuOH solution mixture by adding 1 equivalent of tetrabutylammonium chenodeoxycholic acid salt to the dye solution. The concentration of the dye solution was typically $5 \times 10^{-4} \mathrm{M}$ and the electrodes were dipped for 18-20 hours. The photocurrent action spectra of the N719 sensitizer show broad features covering a large part of the visible spectrum. The incident monochromatic photon-to-current conversion efficiency (IPCE) plotted as a function of excitation wavelength exhibits in the plateau region a value of $87 \%$. Under a standard global AM 1.5 solar conditions (1 sun), the mono-protonated N719 sensitized solar cell exhibited 17.73 $0.5 \mathrm{~mA}$ current, $846 \mathrm{mV}$ potential and fill factor 0.75 (area of the cell: $0.158 \mathrm{~cm}^{2}$ ) yielding an overall conversion efficiency of $11.20 \%$.

\section{Conclusions.}

The sensitizer N719 was synthesised and purified at chromatographic grade. Different and stable species in fast-established equilibria were analysed in solution by mass spectrometry in electrospray ionization (ESI) and identified through the exam of the isotopic patterns. The study in acetonitrile/tert-butanol $(1: 1)$ mixture, used for the adsorption on $\mathrm{TiO}_{2}$, evidenced that the main species involved in the adsorption process is a dicarboxylate species containing one TBA as counterion. Higher polarity favours the formation of ion pairs with two and three TBA counterions and stabilizes di-carboxylates species. An increase in solvent ionic strength upon addition of ammonium acetate favours the association of lypophilic TBA to carboxylate. No cation exchange in ion pairs was observed suggesting the formation of a strong ion pair between TBA and carboxylate. Basic $\mathrm{pH}$ induced deprotonation of carboxylic groups with the formation of tetracarboxylate species with three TBA counterions. 


\section{Aknowledgments}

This work was supported by a contribution from the University of Torino (ex-60\% funds), Regione Piemonte Italy (NANOMAT Project) and EU COST action D35/0007/05. C. Barolo, R. Buscaino, G. Viscardi thank Compagnia di San Paolo and Fondazione CRT, Torino Italy for continuous equipment supplied. MG and MKN acknowledge financial support of this work by the Swiss Federal Office for Energy (OFEN). 


\section{References}

[1] M. Grätzel, Nature 2001, 414, 338.

[2] M. K. Nazeeruddin in Special Issue: Michael Graetzel Festschrift, A tribute for this 60th Birthday: Dye Sensitized Solar Cells., Vol. 248 (Ed. M. K. Nazeeruddin), Elsevier, Amsterdam, 2004, pp. 1161-1511.

[3] J. B. Asbury, R. J. Ellingson, H. N. Gosh, S. Ferrere, A. J. Notzig and T. Lian, J. Phys. Chem. B 1999, 103, 3110-3119.

[4] N.-G. Park, M. G. Kang, K. M. Kim, K. S. Ryu, S. H. Chang, D.-K. Kim, J. Van de Lagemaat, K. D. Benkstein and A. J. Frank, Langmuir 2004, 20, 4246-4253.

[5] T. A. Heimer, E. J. Heilweil, C. A. Bignozzi and G. J. Meyer, J. Phys. Chem. A 2000, 104, 4256-4262.

[6] J.-J. Lee, G. M. Coia and N. S. Lewis, J. Phys. Chem B 2004, 108, 5269-5281.

[7] Y. Saito, N. Fukuri, R. Senadeera, T. Kitamura, Y. Wada and S. Yanagida, Electrochemistry Comm. 2004, 6, 71-74.

[8] P. V. Kamat, M. Haria and S. Hotchandani, J. Phys. Chem B 2004, 108, 5166-5170.

[9] F. L. Qiu, A. C. Fisher, A. B. Walker and L. M. Petecr, Electrochemistry Comm. 2003, 5, 711716.

[10] M. K. Nazeeruddin, R. Humphry-Baker, P. Liska and M. Grätzel, J. Phys. Chem. B 2003, 107, 8981-8987.

[11] M. Adachi, Y. Murata, J. Takao, J. Jiu, M. Sakamoto and F. Wang, J. Am. Chem. Soc. 2004, $126,14943-14949$.

[12] R. Argazzi, G. Larramona, C. Contado and C. A. Bignozzi, Journal of Photochemistry and Photobiology, A: Chemistry 2004, 164, 15-21.

[13] J. Bisquert, D. Cahen, G. Hodes, S. Ruehle and A. Zaban, J. Phys. Chem B 2004, 108, 81068118.

[14] J. Cao, J.-Z. Sun, J. Hong, X.-G. Yang, H.-Z. Chen and M. Wang, Applied Physics Letters 2003, 83, 1896-1898.

[15] M. Durr, A. Bamedi, A. Yasuda and G. Nelles, Applied Physics Letters 2004, 84, 3397-3399.

[16] F. Fabregat-Santiago, J. Garcia-Canadas, E. Palomares, J. N. Clifford, S. A. Haque, J. R. Durrant, G. Garcia-Belmonte and J. Bisquert, J. Appl. Phys. 2004, 96, 6903-6907.

[17] E. Figgemeier and A. Hagfeldt, International Journal of Photoenergy 2004, 6, 127-140.

[18] A. Furube, R. Katoh, T. Yoshihara, K. Hara, S. Murata, H. Arakawa and M. Tachiya, J. Phys. Chem B 2004, 108, 12588-12592.

[19] H. Hongwei, Z. Xingzhong and L. Jian, Journal of the Electrochemical Soc. 2005, 1, 152.

[20] J. H. Kim, M.-S. Kang, Y. J. Kim, J. Won, N.-G. Park and Y. S. Kang, Chem. Comm. 2004, 1662-1663.

[21] T. Miyasaka and Y. Kijitori, Journal of the Electrochemical Society 2004, 151, A1767-A1773.

[22] M. K. Nazeeruddin, R. Humphry-Baker, D. L. Officer, W. M. Campbell, A. K. Burrell and M. Graetzel, Langmuir 2004, 20, 6514-6517.

[23] B. Xue, H. Wang, Y. Hu, H. Li, Z. Wang, Q. Meng, X. Huang, O. Sato, L. Chen and A. Fujishima, Photochemical \& Photobiological Sciences 2004, 3, 918-919.

[24] M. K. Nazeeruddin and M. Gra1tzel in Semiconductor Photochemistry and Photophysics, Vol. 10 Eds.: V. Ramamurthy and K. S. Schanze), Marcel Dekker, New York, 2003, pp. 301-344.

[25] M. Gra1tzel, Comptes Rendus Chimie 2006, 9, 578-583.

[26] M. K. Nazeeruddin, A. Kay, I. Rodicio, R. Humphry-Baker, E. Muller, P. Liska, N. Vlachopoulos and M. Grätzel, J. Am. Chem. Soc. 1993, 115, 6382.

[27] S. Pelet, J. E. Moser and M. Graetzel, J. Phys. Chem. B 2000, 104, 1791-1795. 
[28] D. Cahen, G. Hodes, M. Grätzel, J. F. Guilemoles and I. Riess, J. Phys. Chem. B 2000, 104, 2053.

[29] M. K. Nazeeruddin, S. M. Zakeeruddin, R. Humphry-Baker, S. I. Gorelsky, A. B. P. Lever and M. Graetzel, Coord. Chem. Rev. 2000, 208, 213.

[30] M. Gra1tzel, Nature 2001, 414, 338-344.

[31] M. K. Nazeeruddin, F. De Angelis, S. Fantacci, A. Selloni, G. Viscardi, P. Liska, S. Ito, T. Bessho and M. Gra1tzel, J. Am. Chem. Soc. 2005, 127, 16835-16847.

[32] M. K. Nazeeruddin, S. M. Zakeeruddin, R. Humphry-Baker, M. Jirousek, P. Liska, N. Vlachopoulos, V. Shklover, C. H. Fischer and M. Grätzel, Inorg. Chem. 1999, 38, 6298.

[33] V. B. Di Marco and G. G. Bombi, Mass. Spec. Rev. 2006, 25, 347.

[34] P. Wang, G. R. Newkome and C. Wesdemiotis, 2006, 86, 255. 


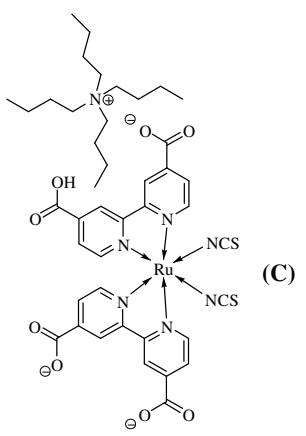

$\mathrm{C}_{42} \mathrm{H}_{49} \mathrm{~N}_{7} \mathrm{O}_{8} \mathrm{RuS}_{2}{ }^{2}$ Exact Mass: 945.21 $\mathrm{z}=2 \mathrm{~m} / \mathrm{z}: 472,61$

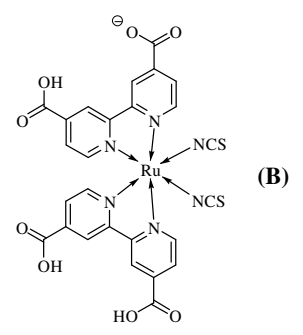

$\mathrm{C}_{26} \mathrm{H}_{15} \mathrm{~N}_{6} \mathrm{O}_{8} \mathrm{RuS}_{2}$ Exact Mass: 704.94
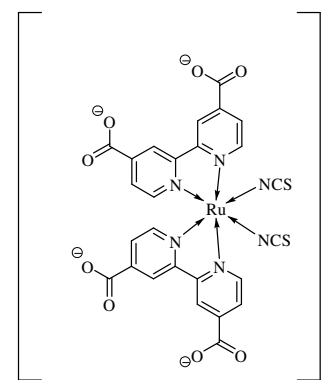<smiles>CCCCN(CCCC)CCCC</smiles>

(D)

$\mathrm{C}_{58} \mathrm{H}_{84} \mathrm{~N}_{8} \mathrm{O}_{8} \mathrm{RuS}_{2}{ }^{2}$

Exact Mass: 1186.49

$\mathrm{z}=2 \mathrm{~m} / \mathrm{z}: 593.24$
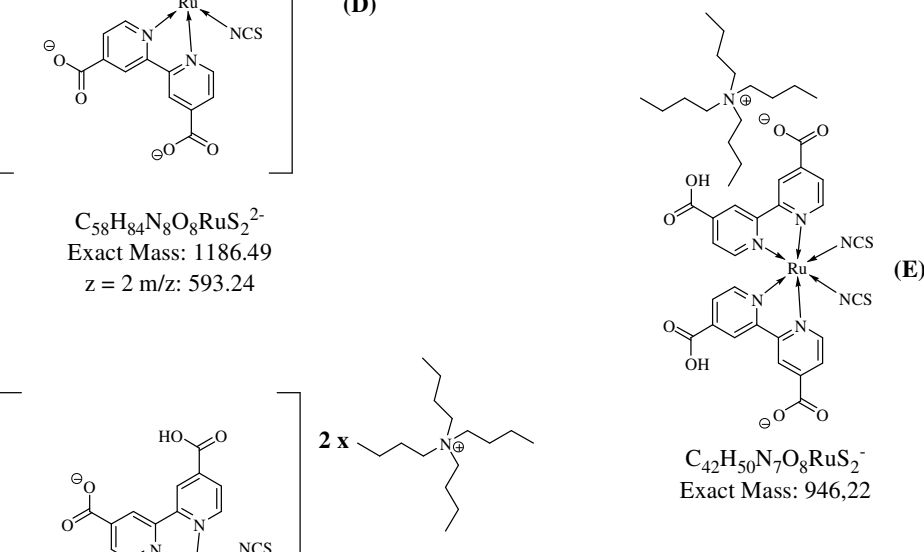

$\mathrm{C}_{42} \mathrm{H}_{50} \mathrm{~N}_{7} \mathrm{O}_{8} \mathrm{RuS}_{2}^{-}$ Exact Mass: 946,22

(E)
$\mathrm{C}_{74} \mathrm{H}_{120} \mathrm{~N}_{9} \mathrm{O}_{8} \mathrm{RuS}_{2}$ Exact Mass: 1428,78

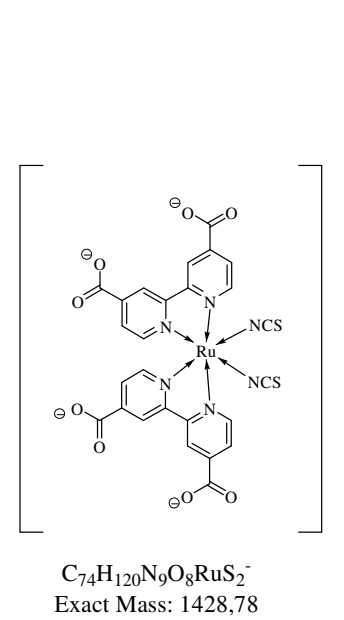

\section{T} $\mathrm{N} 719$
$\mathrm{C}_{58} \mathrm{H}_{86} \mathrm{~N}_{8} \mathrm{O}_{8} \mathrm{RuS}_{2}$ Exact Mass: 1188,51<smiles>CCCCN(CCCC)CCCC</smiles>

(G)

(A)

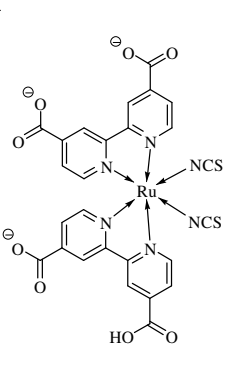

$\mathrm{C}_{58} \mathrm{H}_{85} \mathrm{~N}_{8} \mathrm{O}_{8} \mathrm{RuS}_{2}$ Exact Mass: 1187,5

Scheme 1 N719 Ru(II) complex species observed in solution by ESI experiments. 


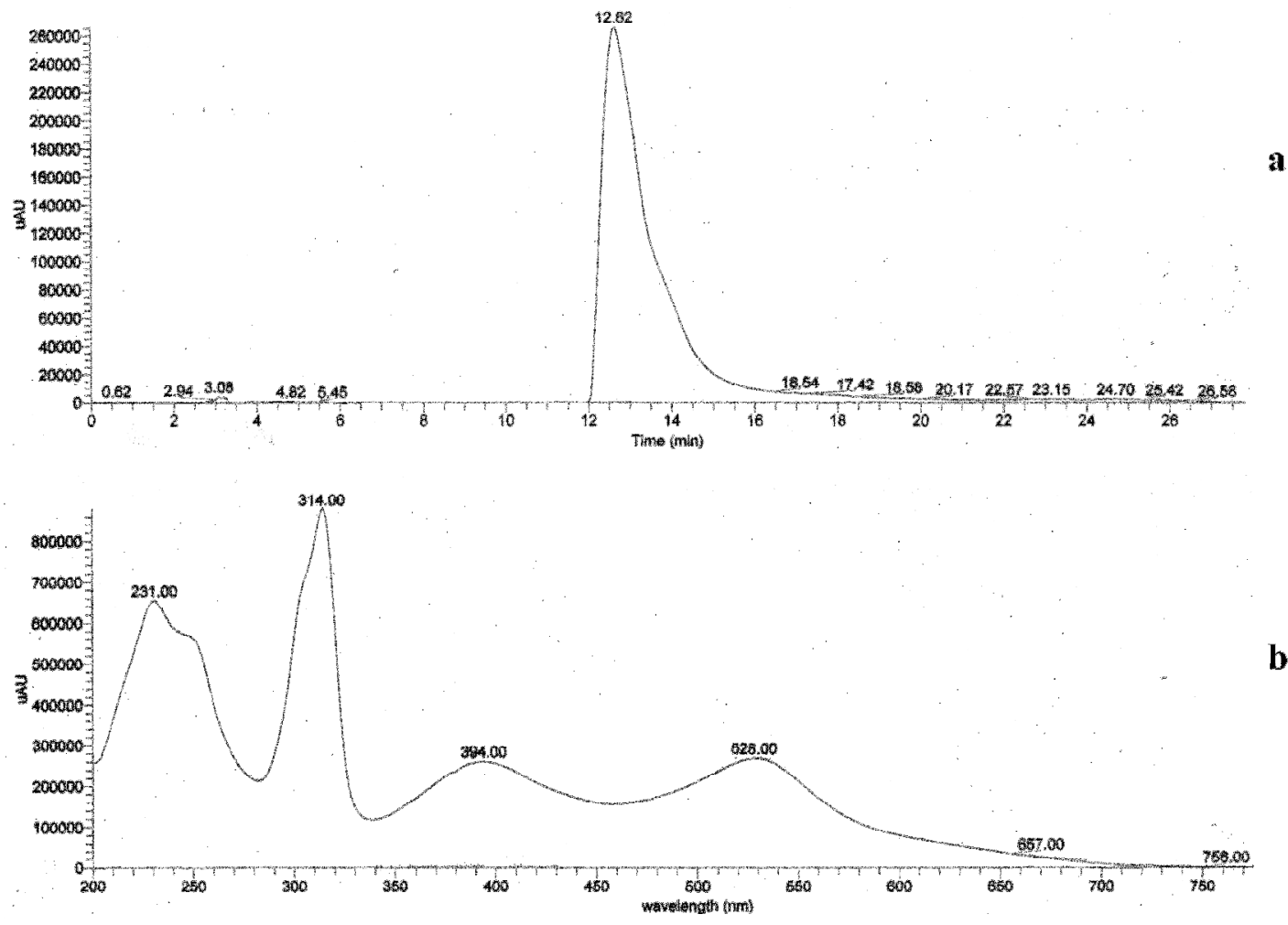

Fig. 1 a) HPLC analysis and b) UV-visible spectrum at peak maximum of $\mathrm{N719}$ Ru(II) complex. 


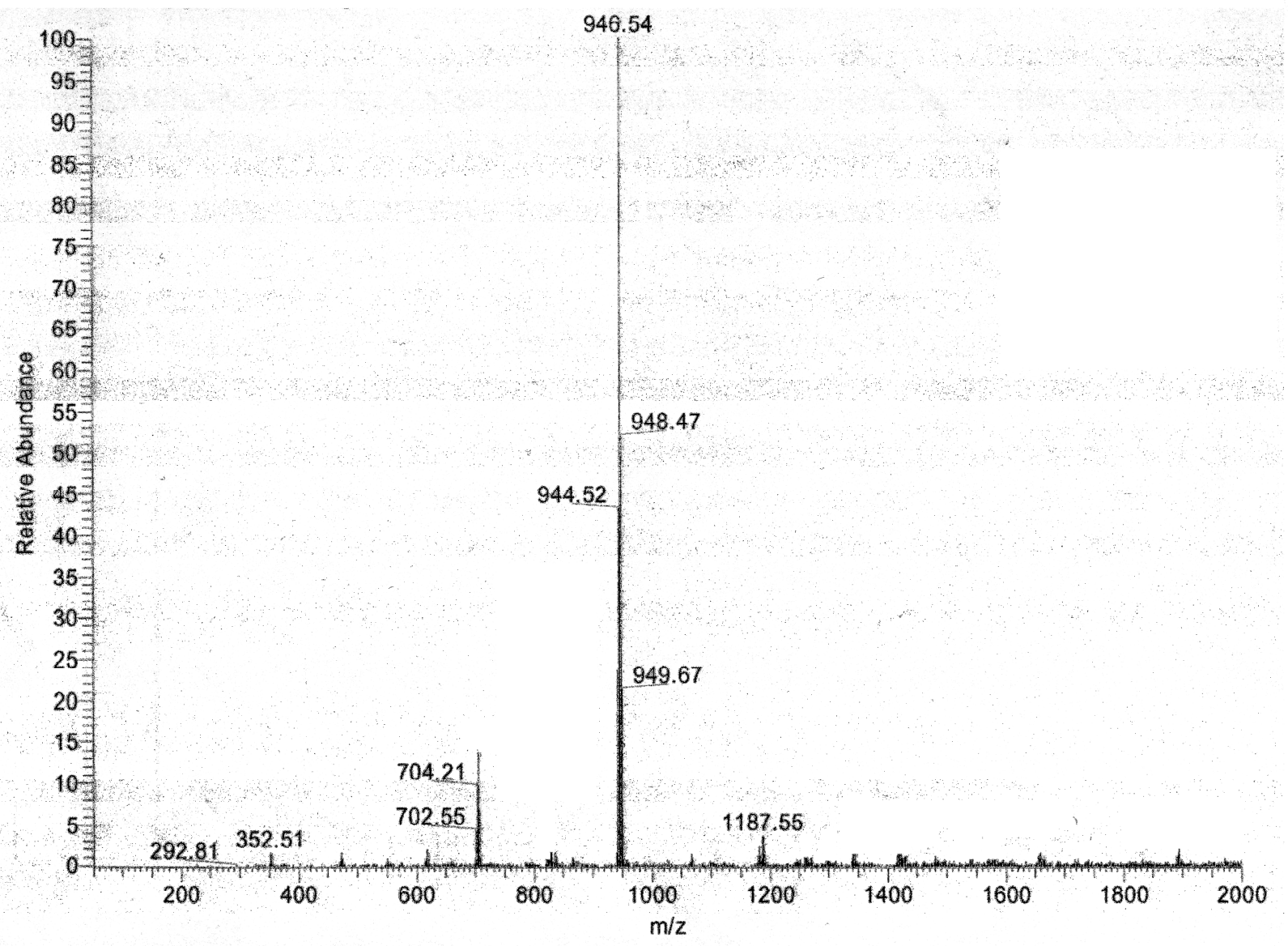

Fig. 2 ESI spectrum of N719 Ru(II) complex in tert-butanol/acetonitrile solution (1:1). 


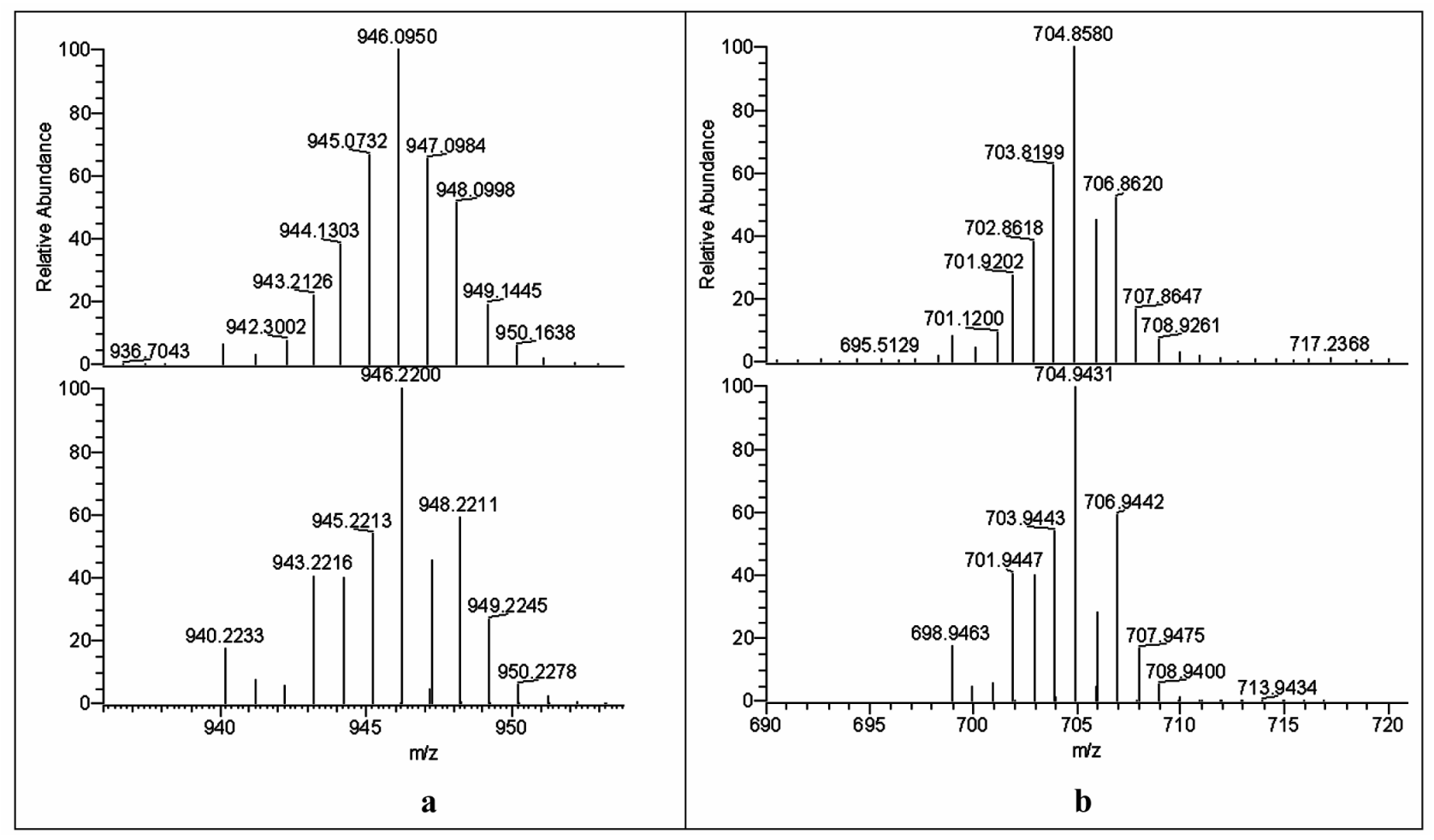

Fig. 3a experimental (top) and calculated (bottom) pattern of peak at $\mathrm{m} / \mathrm{z} 946,1 \mathrm{z}=1,3 \mathrm{~b}$ experimental (top) and calculated (bottom) pattern of peak at $\mathrm{m} / \mathrm{z} 704,9 \mathrm{z}=1$ of $\mathrm{N719} \operatorname{Ru}($ II) complex in tert-butanol/acetonitrile solution (1:1). Spectra at high resolution $(R=80000)$. 


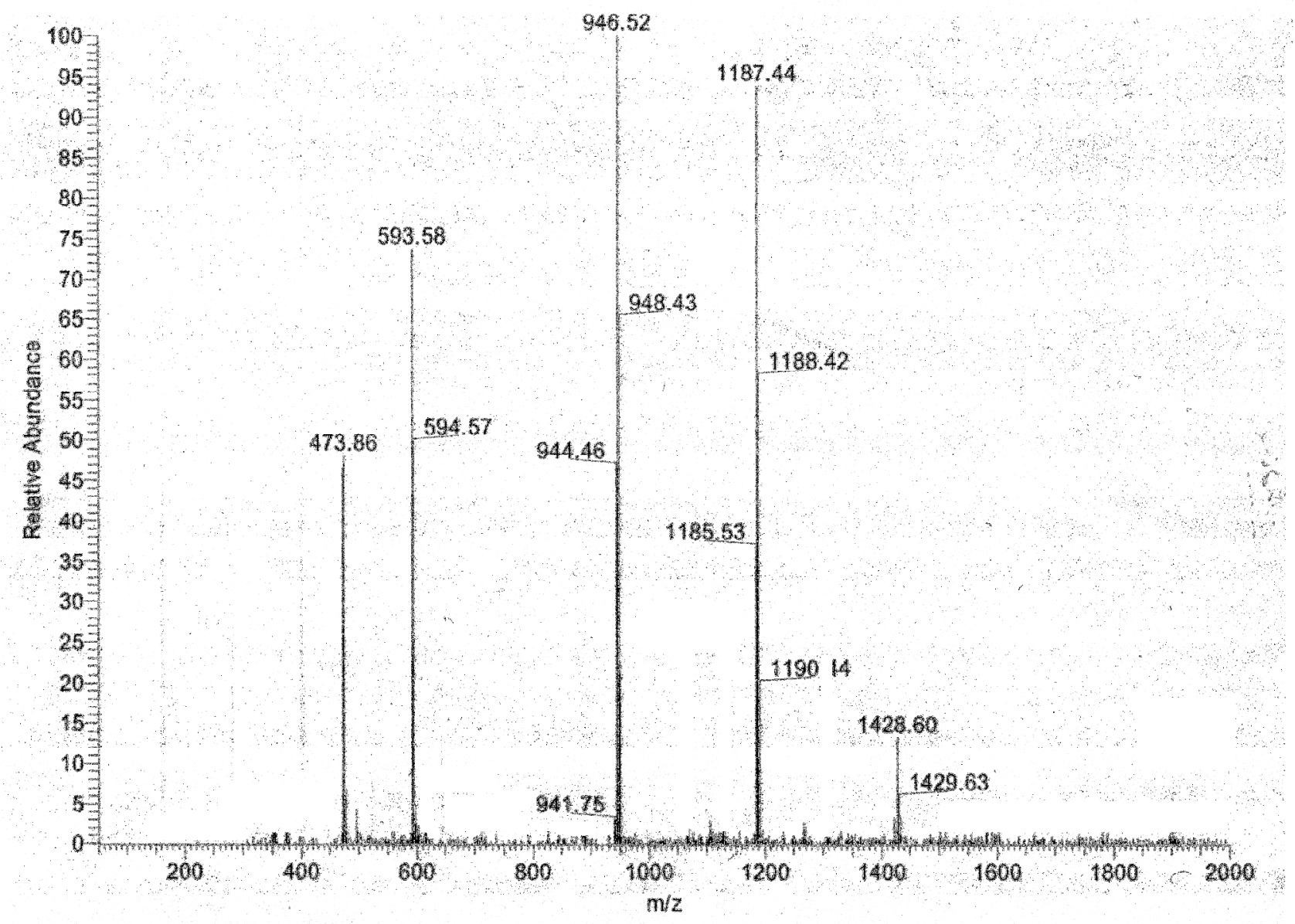

Fig. 4 ESI spectrum of N719 Ru(II) complex in water added with 5\% of methanol. 


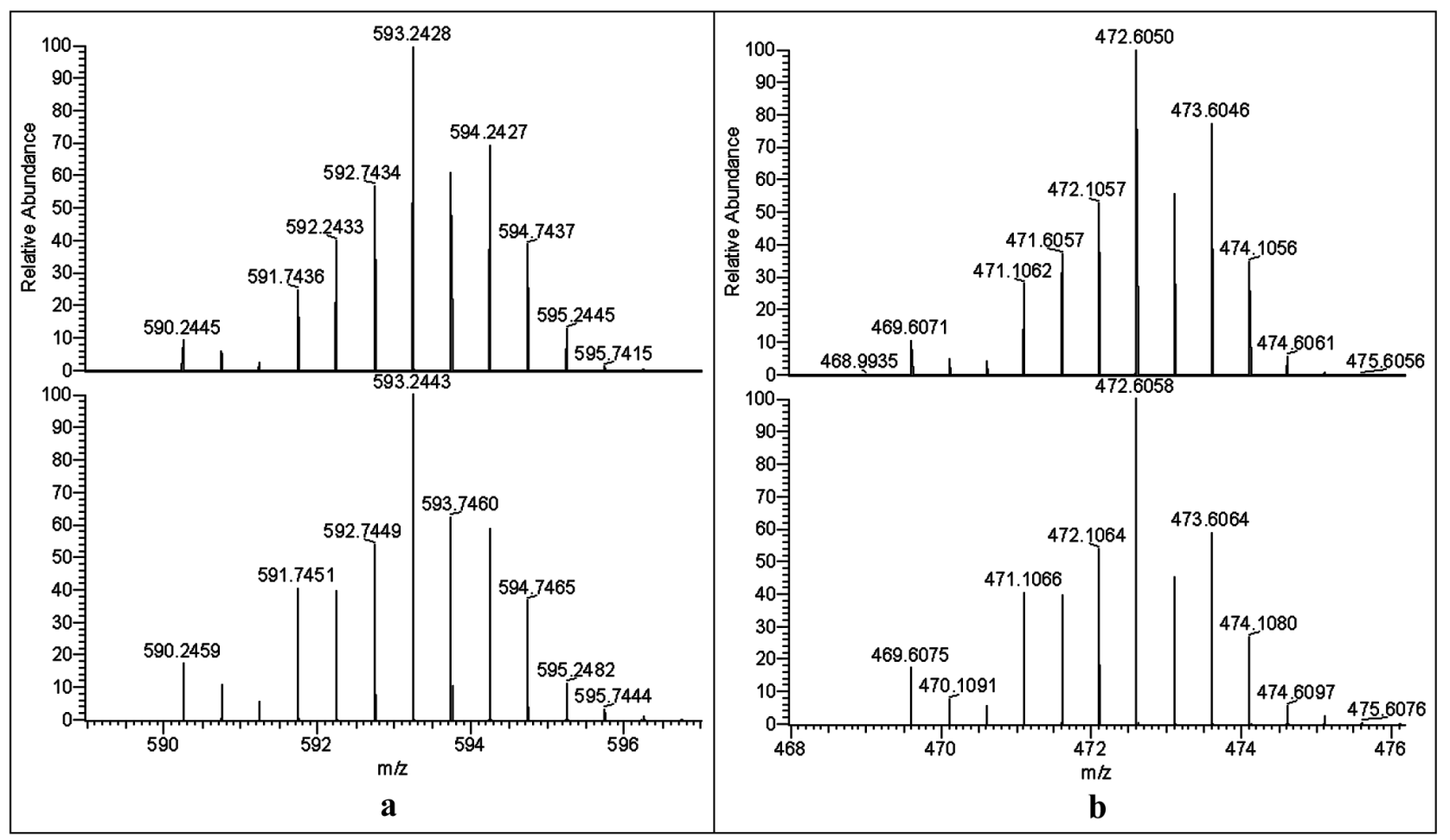

Fig. 5a experimental (top) and calculated (bottom) pattern of peak at $\mathrm{m} / \mathrm{z} 593,2 \mathrm{z}=\mathbf{2}$, $5 \mathrm{~b}$ experimental (top) and calculated (bottom) pattern of peak at $\mathrm{m} / \mathrm{z}$ 472,6 $\mathrm{z}=2$ of $\mathrm{N719} \mathrm{Ru}$ (II) complex in water added with $5 \%$ of methanol. Spectra at high resolution $(\mathrm{R}=\mathbf{8 0 0 0 0})$. 


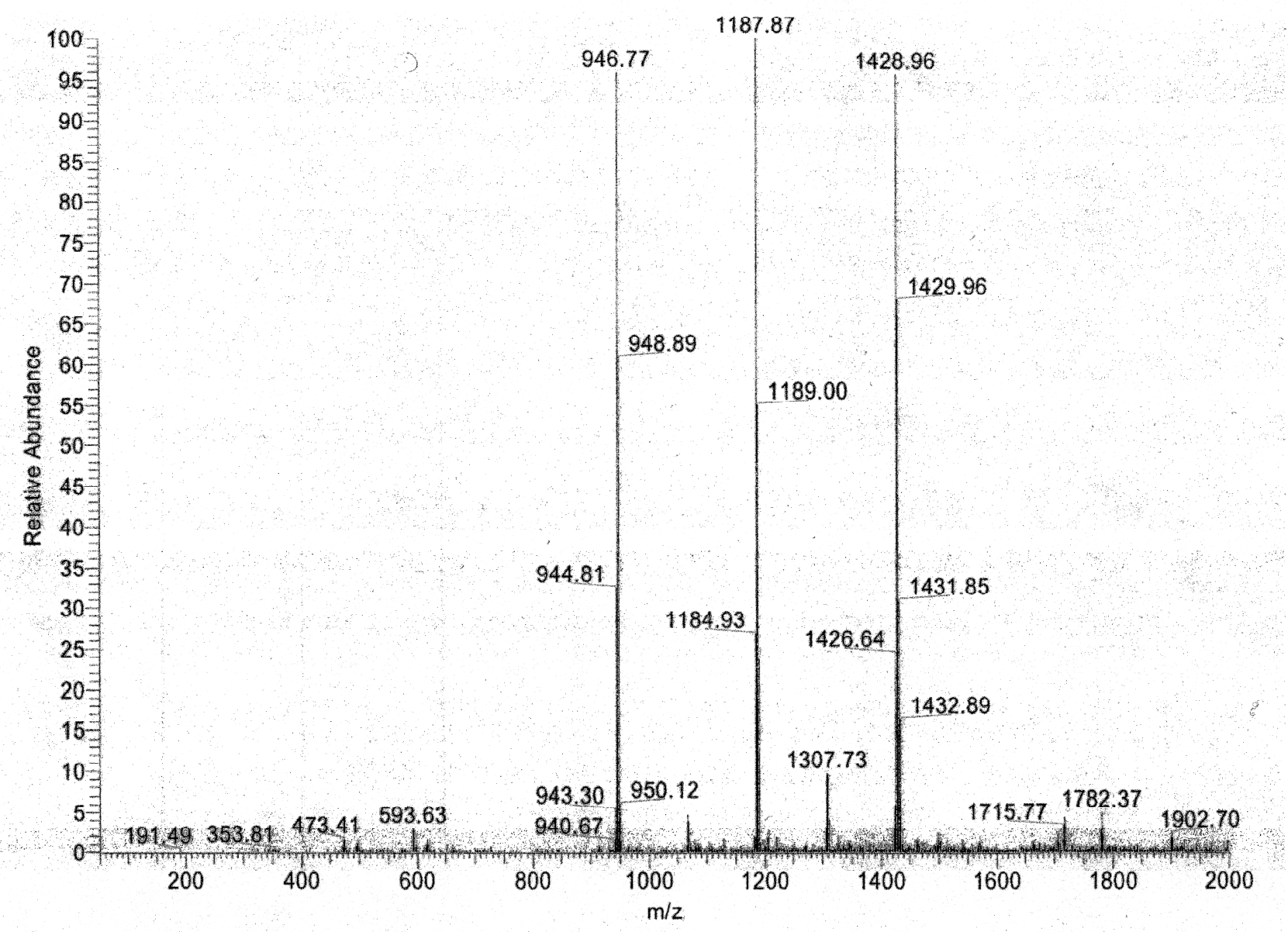

Fig. 6 ESI spectrum of N719 Ru(II) complex in ammonium acetate solution added with $5 \%$ of methanol. 


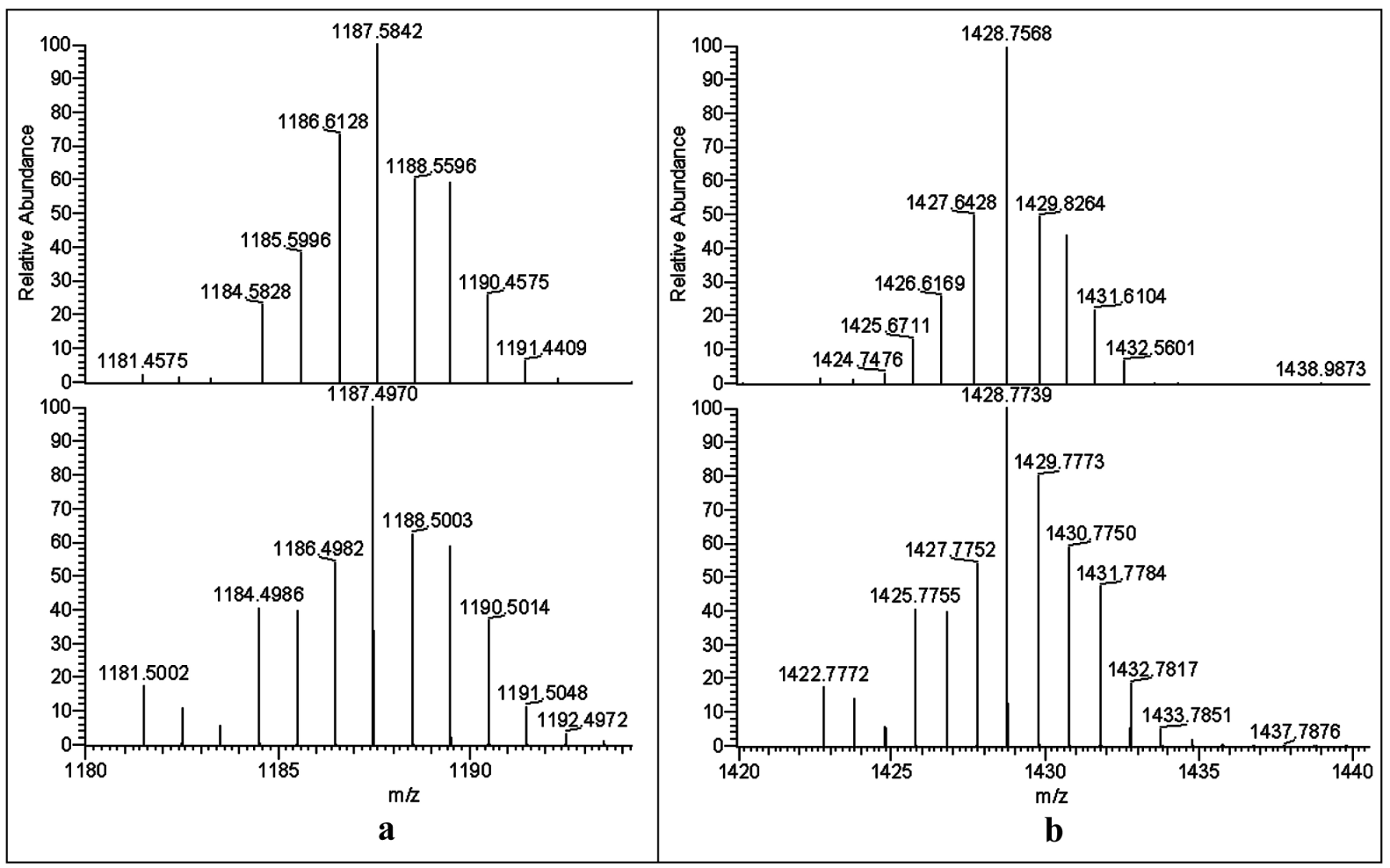

Fig. 7a experimental (top) and calculated (bottom) pattern of peak at $\mathrm{m} / \mathrm{z} 1187,57 \mathrm{~b}$ experimental (top) and calculated (bottom) pattern of peak at m/z 1428,8 of N719 Ru(II) complex in aqueous ammonium acetate $5 \mathrm{mM}$ solution added with $5 \%$ of methanol. 


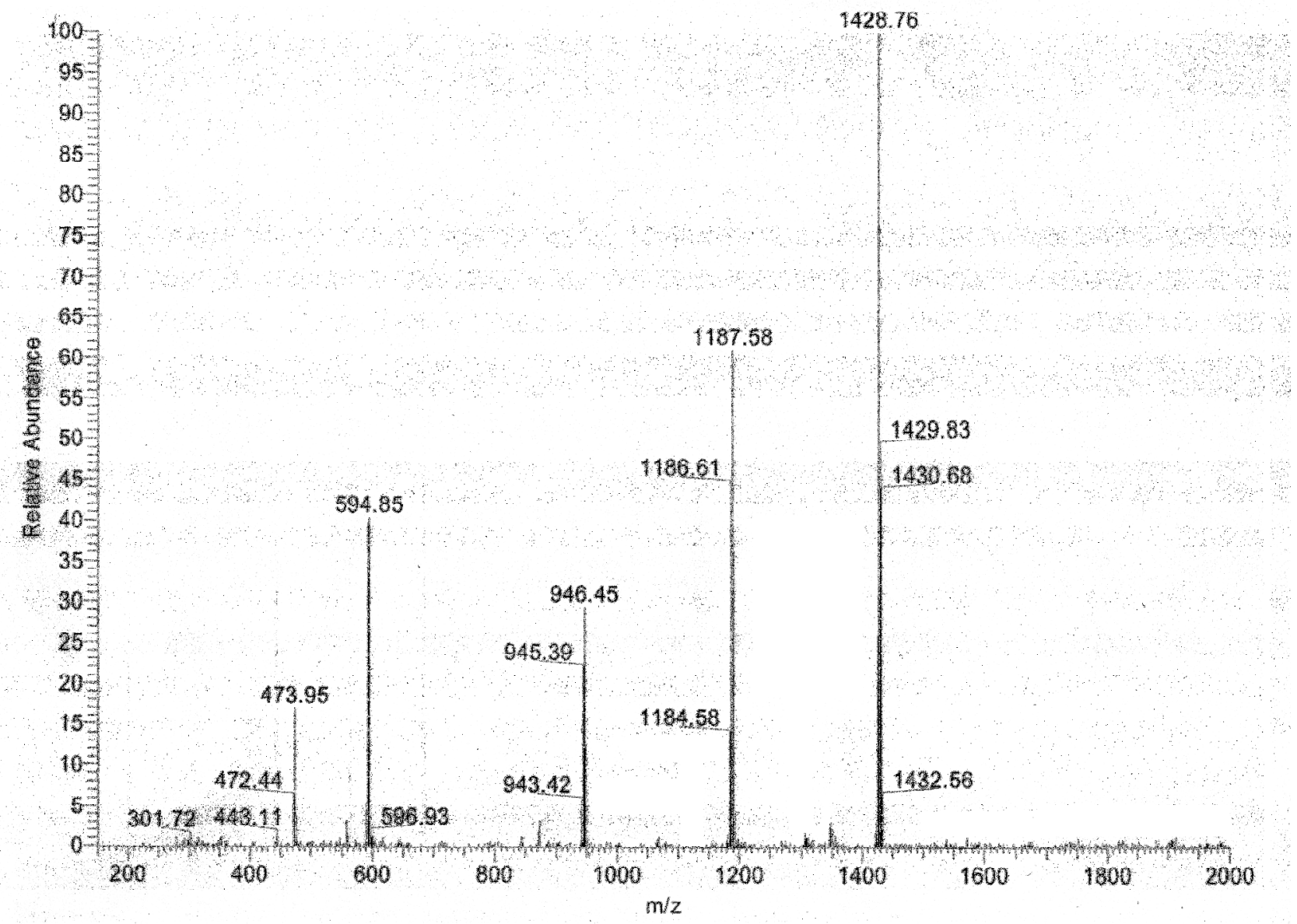

Fig. 8 ESI spectrum of N719 Ru(II) complex in water added with 5\% of methanol, pH set at 12 by addition of ammonium hydroxide. 